\title{
TRICHLOROACETIC AND SOLUBLE ANTIGENS OF SETARIA DIGITATA: CHARACTERIZATION AND CROSS REACTION WITH HUMAN SERUM COMPONENTS
}

\author{
S. DISSANAYAKE AND M. AMARATUNGA \\ Department of Biochemistry, Faculty of Medicine, University of Peradeniya, \\ Peradeniya, Sri Lanka.
}

(Date of receipt: 18 November 1986)

(Date of acceptance : 06 May 1987)

\begin{abstract}
Antigenic cross reactivity between $10 \%$ trichloroacetic soluble antigens of adult Setaria digitata (SDTCA) and components present in human serum and urine were investigated by ELISA and polyethylene glycol precipitation immunoradiometry (PEGIRMA). The usefulness of SDTCA in the serologic diagnosis of Wuchereria bancrofti infections was also investigated. The antibody response to SDTCA in $W$. bancrofti infections was predominantly IgM and SDTCA was not a good antigen for immunodiagnosis by antibody determination. Evidence supporting antigenic cross reactivity between trichloroacetic acid soluble antigens of $S$. digitata and human immunoglobulin carbohydrates is presented. Rabbit antisera to human immunoglobulins, human immunoglobulin carbohydrates, $10 \%$ trichloroacetic acid soluble components in normal human serum and adult $S$. digitata showed the same degree of reactivity with radiolabelled human immunoglobulins. Immunoreactive components were detected in the urines of filarial patients by dot ELISA with rabbit antisera to SDTCA. False positive reactions were observed due to cross reactions with catabolic products excreted in urine.
\end{abstract}

\section{Introduction}

Antigenic similarities between polysaccharides of nematode parasites and mammalian blood group substances were known for many decades. ${ }^{19,20,21,22,29}$ Smith et al. ${ }^{28}$ have shown that such molecules are expressed on the surface and excretions/ secretions of in vitro maintained second stage larve of Toxocara canis.

Sharing of host antigens and/or antigenic cross reactivities between molecules of filarial parasites and host tissue components have been described previously in Onchocerca volvulus ${ }^{19}$, Wuchereria bancrofti ${ }^{27}$ and Litomosoides carinii $23,24,30$ and the discussion has been on the possible. mechanisms of evasion of the host immune response. ${ }^{2,16}$

The availability of a specific immunodiagnostic test could be of much value in the control of filarial infections and the current emphasis is on the development of antigen detection assays. ${ }^{6,7,8,25,26,32}$ Sharing of antigens between the host and the parasite could affect the specificity and sensitivity of both antigen and antibody detection systems, ${ }^{7,14}$ particularly in situations such as bancroftian filariasis where heterologous antigens are 
relatively indispensable as at present.

In this communication we present evidence to demonstrate antigenic cross reactivity between human immunoglobulin carbohydrates and trichloroacetic acid soluble carbohydrate antigens of the heterologous filarial parasite Setaria digitata.

\section{Materials and Methods}

\subsection{Blood serum and urine from filarial patients and controls}

Blood serum and urine were collected from $W$. bancrofti infected patients (both microfilaraemic and amicrofilaraemic) attending an Anti-Filariasis clinic. Microfilaraemia was determined by the membrane filtration technique. The diagnosis of clinical cases was based on the indirect immunofluorescence test using $W$. bancrofti microfilariae 12 and characteristic symptoms such as elephantiasis, lymphoedoma, lymphangitis and response to DEC treatment. Sera from non-filarial subjects (absence of clinical signs/ symptoms and of serum antibodies by ELISA and IFA) from the filariasis endemic and non-endemic areas were also collected.

\subsection{Carbohydrate antigens of S. digitata}

Solubility in $10 \%$. Trichloroacetic acid (10\% TCA) was the criterion used for isolation of carbohydrate like antigens. Adult $S$. digitata worms were collected from the peritoneal cavity of cattle slaughtered at the municipal abbatoir, Kandy, Sri Lanka. The parasites were transported in normal saline, washed and TCA-soluble antigens were extracted by homogenisation in $10 \%$ TCA, dialysed against phosphate buffered saline (PBS pH 7.4), concentrated and stored at $-20^{\circ} \mathrm{C}$ in aliquots. This antigen preparation was denoted as SDTCA.

\subsection{Antigen SD2-4 of $S$. digitata}

Antigen SD2-4 from adult S. digitata was prepared as described previously. ${ }^{3}$

\subsection{TCA-Soluble components in normal human serum (NHSTCA)}

Trichloroacetic acid (TCA) soluble components in normal human serum (NHSTCA) were prepared by extraction with $10 \%$ TCA. To approximately $50 \mathrm{ml}$ of pooled human sera, TCA was added to produce a final concentration of $10 \%$, the mixture homogenised and the soluble components isolated by centrifugation. The supernate was dialysed against PBS ( $\mathrm{pH} 7.4$ ), concentrated 5:1 and stored at $-20^{\circ} \mathrm{C}$. 


\subsection{Normal human Immunoglobulin (NHIg)}

Normal human immunoglobulin (NHIg) was prepared by DEAE-Cellulose chromatography 10 from Cohn Fraction II (Sigma Chemicals).

\subsection{Carbohydrates from human immunoglobulins (HIgCHO)}

Human immunoglobulins isolated by DEAE-Cellulose chromatography were digested with protease (insoluble enzyme attached to $\mathrm{CM}-$ Cellulose, from Streptomyces griseus, Sigma Chemical Co. Ltd) at $37^{\circ} \mathrm{C}$ for $12 \mathrm{hrs}$. The carbohydrates were isolated by dialysis and concentrated.

\subsection{Concentrated and dialysed urine from non-filarial subjects (CDNU)}

Twenty four-hour urine samples were collected from normal subjects living in areas non-endemic for filariasis, pooled, concentrated $(10: 1)$ by dialysis against solid sucrose and PBS and stored at $-20^{\circ} \mathrm{C}$.

\subsection{Concentrated and dialysed urine from filarial patients (CDFilU)}

Concentrated and dialysed urine samples from filarial patients were prepared similarly. The filarial patients were $W$. bancrofti infected and all the patients were symptomatic and had serum antibodies to $W$. bancrofti microfilarial surface antigens by immunofluorescence.

\subsection{Labelling of antigen preparations with 125 Iodine}

Antigen preparations were labelled with 125 Iodine (IMS 30, Amersham Radiochemicals, UK) by the method of Hunter \& Greenwood. ${ }^{11}$

\subsection{Preparation of rabbit antisera to SDTCA, SD2-4, NHIg, NHSTCA, $\mathrm{HIgCHO}, \mathrm{CDNU}$ and CDFilU}

Rabbits were immunised with SDTCA, SD2-4, NHIg, NHSTCA, HIgCHO, CDNU and CDFilU in Complete Freund's Adjuvant, intramuscularly at the hind leg region. Three or four animals were used for each antigen. Booster immunizations were given in Incomplete Freund's Adjuvant at 10 day intervals through the same route. Test bleeding commenced 10 days after the third booster immunization. The sera were tested by ELISA against the immunising antigen and, when the antibody titre was above 1:500, the animals were bled.

\subsection{Determination of total protein and carbohydrate levels}

The levels of total protein and carbohydrate in antigens and urines were determined by the Lowry method ${ }^{15}$ and the Phenol-Sulphuric acid method 
of Norris \& Ribbons ${ }^{18}$ respectively.

\subsection{SDS polyacrylamide gel electrophoresis (SDSPAGE) \& Western Blotting}

SDSPAGE was performed in vertical gel slabs of $7.5-10.0 \%$ gel strength in phosphate buffer $(\mathrm{pH} 7.1,0.1 \mathrm{M})$ and Western blotting according to the method of Towbin et al. ${ }^{31}$ and Batteiger et al. ${ }^{1}$ SDSPAGE gells were stained with Coomassie Blue or Periodate-Schiff reagent (Sigma Chemicals) and the Western blots were reacted with hyperimmune sera from animals immunised with filarial antigens and sera from $W$. bancrofti infected patients. The development of Western blots was by ELISA using Peroxidase conjugated antisera (Cáppel Laboratories, Cochranville, USA) and $0.3 \% 4-$ chloro-1napthol as substrate (Sigma Chemicals).

\subsection{ELISA in microtitre plates}

Microtitre plate ELISA was carried out using Dynatech PVC round bottomed plates (SDTCA showed better binding to PVC plates compared to polystyrene). The antigen was coated in carbonate buffer $\mathrm{pH} 9.6,0.06 \mathrm{M}$ at a predetermined concentration of $10 \mu \mathrm{g} / \mathrm{ml}$ and the reaction volume was maintained at $100 \mu \mathrm{l}$ per well. Sera were tested at both fixed and serial dilutions. Peroxidase-linked anti-human IgM (Fc specific) and anti-human Ig (IgA+IgM+IgG) were obtained from Cappel Laboratories, USA and ureaseconjugated anti-human. IgG (affinity purified) was from Commonwealth Serum Laboratories, Melbourne, Australia. ELISA reactivity in peroxidase ELISA was determined by reading absorbance at $492 \mathrm{~nm}$ (read on Titretek plate reader). With IgG-urease conjugate, colour change to purple in 20 minutes was considered positive.

\section{2:14 DOT ELISA on Nitrocellulose}

A dot ELISA procedure was developed for the detection of antigens in urine. Five $\mu \mathrm{I}$ of urine or predetermined dilutions of antigen preparations were spotted on to nitrocellulose paper and air dried. The unbound sites on the paper were then blocked with bovine serum albumin (BSA) and Tween 20 in PBS $(0.5 \% \mathrm{BSA}, 0.05 \% \mathrm{~T} 20)$ at $37^{\circ} \mathrm{C}$ for 3 hours. The paper was then reacted with hyperimmune sera followed by the enzyme-antibody conjugate and colour developed with 3\% 4-Chloro-1-Napthol (Sigma) in citrate buffer, $\mathrm{pH}$ 5.0.

\subsection{Polyethylene glycol-Immunoradiometry (PEGIRMA)}

All radio-immunoprecipitations were carried out in polystyrene tubes (LP3, Lukham Ltd, England) coated with a $1 \%$ solution of gelatin. All reactions were carried out in PBS containing BSA and Tween 20 (PBS, pH 7.4, 0.1 M; 
$0.5 \%$ BSA; $0.05 \%$ Tween 20; PBS-BSA-T). ${ }^{125}$ Iodine labelled antigens (approximately $20,000 \mathrm{cpm} /$ tube, final reaction volume, $0.5 \mathrm{ml}$ ) were incubated in duplicate with different, serially diluted antisera at $37^{\circ} \mathrm{C}$ for 3 hrs and overnight at $4^{\circ} \mathrm{C}$. An equal volume of $20 \%$ polyethylene glycol (PEG, MW 6000, Sigma Chemicals) in PBS-BSA-T20 was then added, mixed well and incubated at $4^{\circ} \mathrm{C}$ overnight. The tubes were then centrifuged at $1000 \mathrm{~g}$ for 10 minutes at $4^{\circ} \mathrm{C}$ and the precipitate washed ( $5 \mathrm{x}$ times) with cold $10 \%$ PEG in PBS. The radioactivity in the precipitate was determined.

\section{Results}

\subsection{Composition of SDTCA and concentrated urines}

The approximate concentrations of protein and carbohydrate in the $10 \%$ trichloroacetic acid extract of adult $S$. digitata (SDTCA) were $300 \mu \mathrm{g} / \mathrm{ml}$ of protein and $20 \mathrm{mg} / \mathrm{ml}$ of carbohydrate (as glucose units) respectively (protein : carbohydrate ratio 1:66). SDTCA on SDSPAGE showed seven Coomassie Blue staining bands (molecular weight range $10 \mathrm{~K}-100 \mathrm{~K}$ ). Contrary to expectation, Periodate-Schiff staining was weak and showed two broa'd bands of approximate molecular weight $50 \mathrm{~K}-100 \mathrm{~K}$. More than $95 \%$ of total carbohydrate in SDTCA was in the excluded fraction by sephadex G200 gel filtration. CDFilU contained $880 \mu \mathrm{g} / \mathrm{ml}$ of protein and $400 \mu \mathrm{g} / \mathrm{ml}$ of carbohydrate as glucose units. On SDSPAGE, CDFilU showed 4 Coomassie Blue staining bands of molecular weight range $15 \mathrm{~K}-75 \mathrm{~K}$ and 2 bands of molecular weight $60 \mathrm{~K}-70 \mathrm{~K}$ with Periodate-Schiff reagent. CDNU contained $790 \mu \mathrm{g} / \mathrm{ml}$ protein, $180 \mu \mathrm{g} / \mathrm{ml}$ carbohydrate and the same SDSPAGE pattern as CDFilU. Sephadex G200 gel filtration of CDNU and CDFilU showed carbohydrates in the excluded fraction and in the molecular weight range $40-60 \mathrm{~K}$.

\subsection{Serum Antibody to SDTCA in W. bancrofti infections}

The levels of antibodies reacting with antigen SDTCA in the sera of a representative group of $W$. bancrofti patients and non-filarial subjects are shown in Table 1. Antibodies reacting with SDTCA were not filarial specific. Levels of antibodies in filarial patients were not significantly different from those of non-filarial subjects. A relative absence of IgG antibody reacting with SDTCA determinants was observed (Table 1). The levels of total antibody $(\operatorname{IgG}+\operatorname{IgM}+\operatorname{IgE})$ reacting with SDTCA in ELISA correlated well with the level of IgM antibody (Pearson's $\mathrm{R}=0.63, \mathrm{p}<0.05$ ) but the total antibody did not correlate with the level of antibodies other than IgM $(\operatorname{IgG}+\operatorname{IgA}+\operatorname{IgE}$, Pearson's $R=0.05$, correlation not significant). 
Table 1. Levels of antibodies reacting with SDTCA in ELISA in a representative group of Wuchereria bancrofti infected and control subjects.

\begin{tabular}{|c|c|c|c|}
\hline Subject Group & $\begin{array}{l}\text { Antibody Levels, } \\
\text { Mean } \pm \text { S.D. } \\
\text { Total Ab. }\end{array}$ & $\begin{array}{l}\text { LISA OD } 492 \\
(\% \text { seropositive*) } \\
\text { IgM Ab. }\end{array}$ & $\begin{array}{l}\text { IgG antibody, } \\
\text { Urease**: } \\
\text { No. positive }\end{array}$ \\
\hline Elephantiasis. $(\mathrm{N}=16)$ & $0.31 \pm 0.07(12)$ & $0.19 \pm 0.12(6)$ & 5 \\
\hline Lymphoedema. $(\mathrm{N}=40)$ & $0.29 \pm 0.07(7)$ & $0.28 \pm 0.35(10)$ & 17 \\
\hline Microfilaremic. $(\mathrm{N}=5)$ & $0.24 \pm 0.09(0)$ & $0.19 \pm 0.06(0)$ & 1 \\
\hline Nonendemic Controls. $(\mathrm{N}=16)$ & $0.24 \pm 0.08(0)$ & $0.15 \pm 0.09(6)$ & 3 \\
\hline
\end{tabular}

Pearsons's Correlation between total antibody (Total, $\mathrm{A}_{492}$ ) and IgM antibody (IgM, $A_{492}$ ) for the total subjects $R=0.63, p<0.05$.

Pearson's Correlation between total antibody (Total $\mathrm{A}_{492}$ ) and other antibody (Total, $\mathrm{A}_{492}-\operatorname{IgM} \mathrm{A}_{492}$ ), $\mathrm{R}=0.05$, not significant.

* $A_{492}$ greater than mean $+2 . S D$ of the non endemic control group was considered seropositive.

** Urease Conjugated affinity purified anti-human IgG.

Serum antibodies in patients reacting with SDTCA were also investigated by SDSPAGE-Western blotting. Different patients' sera showed different staining patterns and did not have any correlation with the disease type. The Western blot bands were broad and diffuse and estimation of molecular weight was difficult. Some filarial sera showed up to 6 bands of molecular weight range $15 \mathrm{k}$ to $70 \mathrm{k}$, while non-filarial sera detected up to 3 bands, generally of molecular weight range higher than $60 \mathrm{k}$. The bands of molecular weight less than $60 \mathrm{k}$ appeared to be reacting only with filarial sera. Table 2 gives a representative summary of the results of SDSPAGE Western blotting. The bands detected by Western blotting did not overlap with Coomassie blue staining bands. 


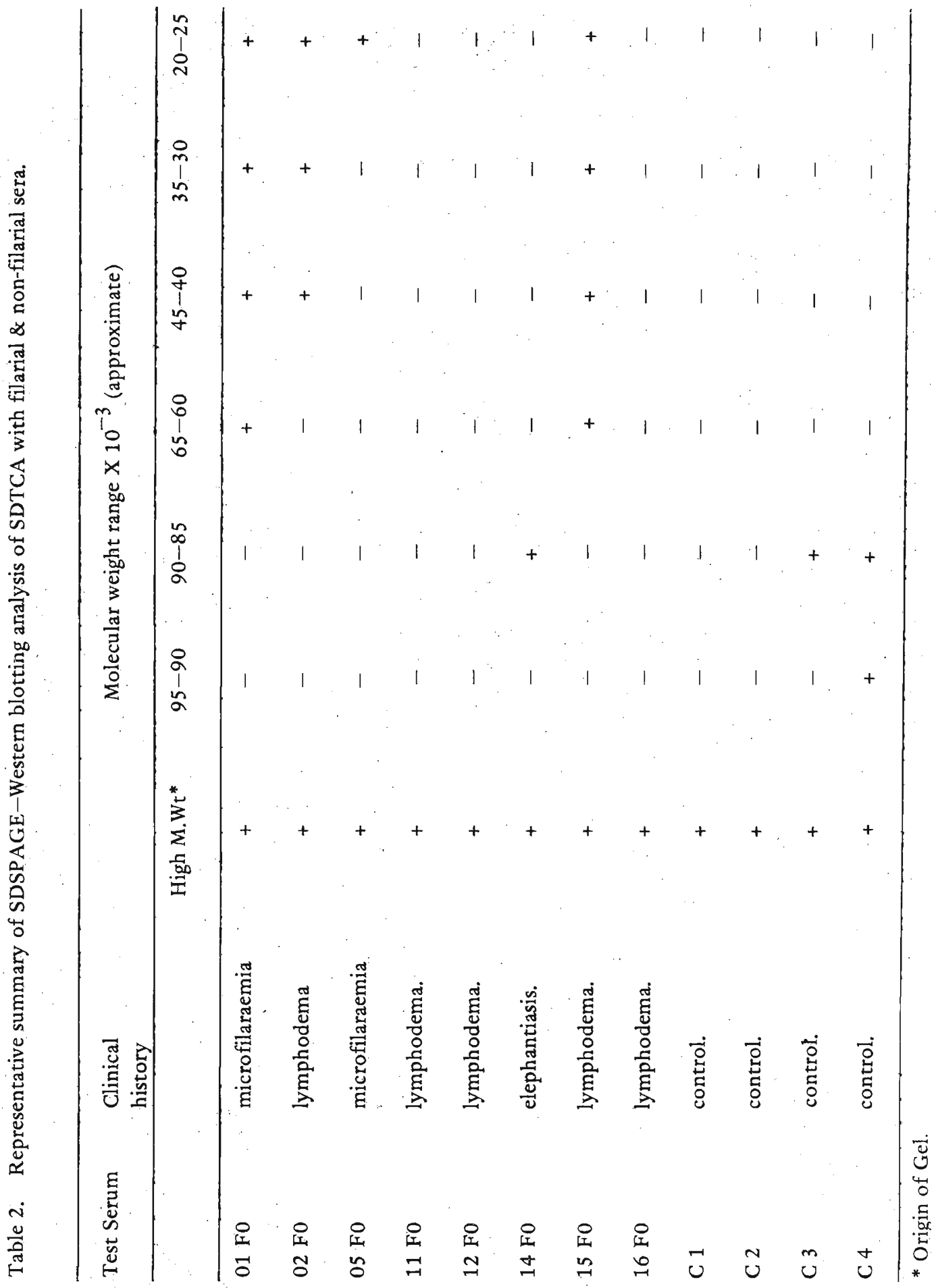




\subsection{Reactivities of rabbit antisera to antigens SD2-4, SDTCA, NHSTCA,} CDFiIU, human Ig and HIgCHO with SDTCA in ELISA

In Figure 1 are shown the relative ELISA reactivities of rabbit antisera to SD2-4, TCA-soluble antigens of $S$. digitata (SDTCA), TCA soluble components of normal human serum (NHSTCA), concentrated filarial urine (CDFilU), human Ig and human Ig carbohydrate (HIgCHO) with SDTCA. All antisera showed reactivity with SDTCA as compared to normal rabbit serum.

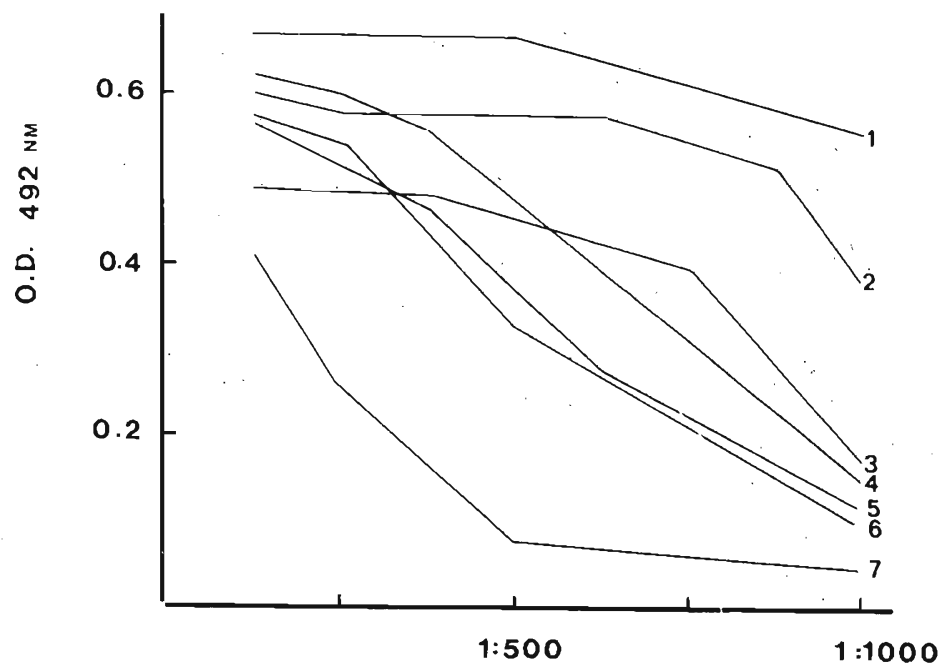

SERU M DILUTION

Figure 1. Relative ELISA reactivities of rabbit antisera made against filarial antigens and human serum and urine components with SDTCA antigen. All assays were performed in $5 \%$ normal goat serum, $0.5 \%$ bovine serum albumin and $0.05 \%$ tween 20 . Each point represents the mean of 3 assays. Antigen SDTCA was coated at $5 \mu \mathrm{g} / \mathrm{ml} .1=$ rabbit anti $\mathrm{Sd} 2-4,2=$ rabbit anti SDTCA, 3 = rabbit anti NHSTCA, $4=$ rabbit anti CDFilU, $5=$ rabbit anti human Ig, $6=$ rabbit anti $\mathrm{HIgCHO}$ and $7=$ normal rabbit serum pool. The conjugate used was goat anti rabbit Ig-Peroxidase absorbed against $\mathrm{CNBr}-\mathrm{Sepharose}$ 4B insolubilised human Ig. 


\subsection{Reactivity of rabbit antisera to filarial antigens, human serum compo- nents and human urine components with radiolabelled antigens as determined by PEGIRMA}

Radiolabelled human Ig (NHIg) and TCA-soluble components in normal human serum (NHSTCA) when used as antigen in PEGIRMA reacted to the same extent with rabbit antisera to human Ig, human Ig carbohydrates, TCA soluble components in normal human serum (NHSTCA) and TCA soluble antigens of $S$. digitata (SDTCA). However, radiolabelled SDTCA did not show the converse reaction, possibly because the cross reacting epitope bearing molecules were not radiolabelled. Similarly rabbit antisera to concentrated filarial and non-filarial urines reacted with radiolabelled human Ig and NHSTCA. Antigens. SDTCA and concentrated urines could not be labelled by the Chloramine $\mathrm{T}$ method to the same specific activities as human Ig and NHSTCA. This may account for the poor reactivity of SDTCA and concentrated urines as antigens in PEGIRMA. These results are summarised in Table 3.

\subsection{Dot ELISA with concentrated urines}

The goat anti-rabbit Ig-peroxidase conjugate reacted with $100 \%$ of the urines as detected by dot ELISA, and this reactivity was abolished when the conjugate was absorbed with human Ig (Table 4). Rabbit antiserum to SDTCA detected reactive components in $26 \%$ of the filarial urines and $12 \%$ of non-filarial urines. Greater part of this reactivity of the rabbit antiSDTCA antiserum with urine, was abolished when the anti-SDTCA antiserum was absorbed with $\mathrm{CNBr}$-Sepharose $4 \mathrm{~B}$-insolubilised human Ig. The residual reactivity with normal urines could not be removed by exhaustive and repeated absorption of the antiserum (see discussion). The antiserum to human Ig carbohydrate showed similar reactivity. These results are summarised in Table 4 . The dot ELISA reacting components in concentrated urines were restricted to the excluded fractions in Sephadex G200 gel filtration (data not shown).

\section{Discussion}

Studies on carbohydrate antigens of filarial parasites are relatively scarce. However the few reports available $4,5,6,8,25,26,32$ indicate that carbohydrates form an important group of antigens in filarial infections.

The $10 \%$ trichloroacetic acid soluble molecules of adult $S$. digitata were predominantly carbohydrate (protein: carbohydrate $=1: 66$ ). Although serum antibodies reacting with these carbohydrates could be detected in $W$. bancrofti infections, the differences between the antibody levels of filarial patients and non-filarial subjects was not sufficient to be of diagnostic 


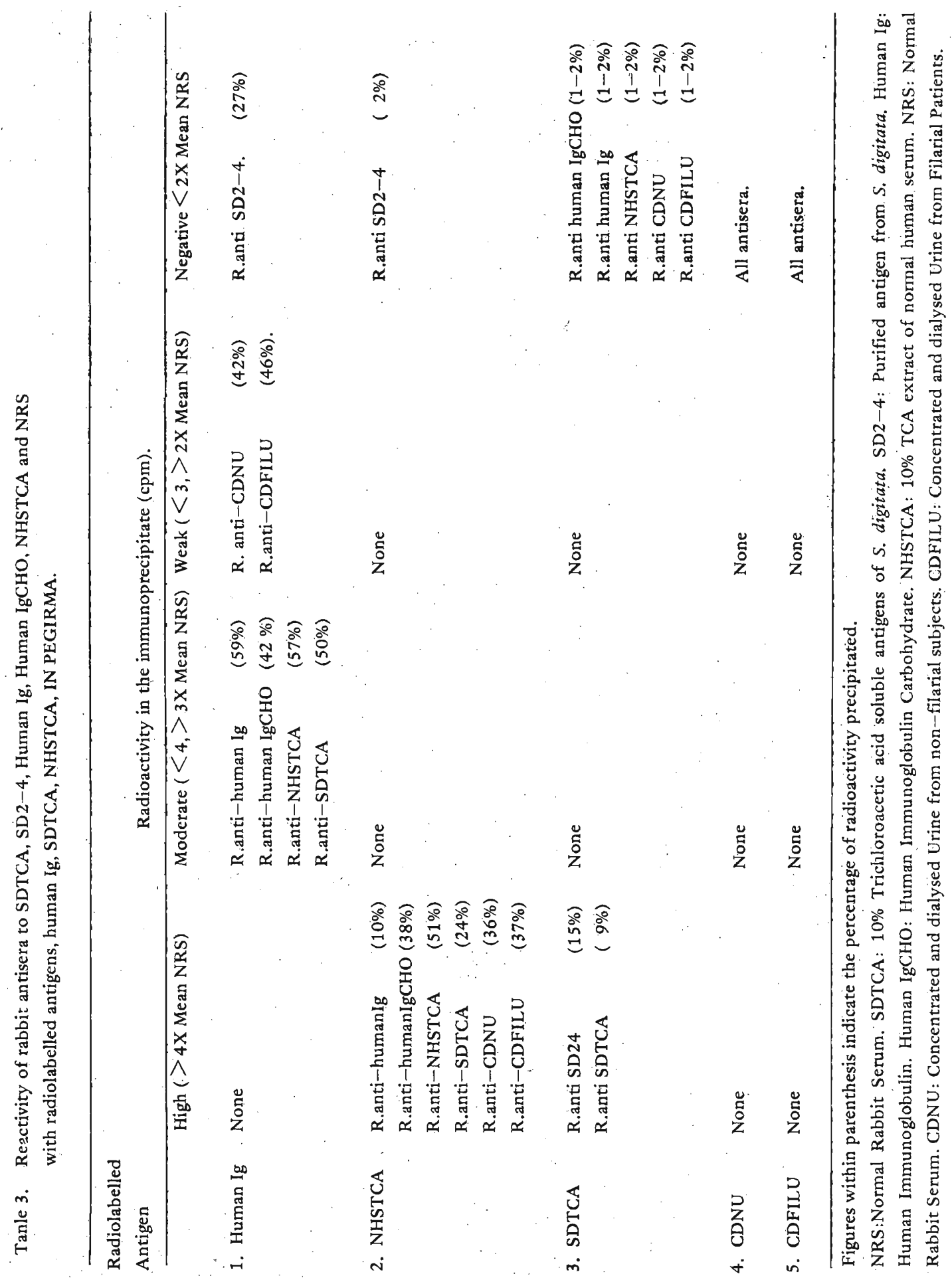




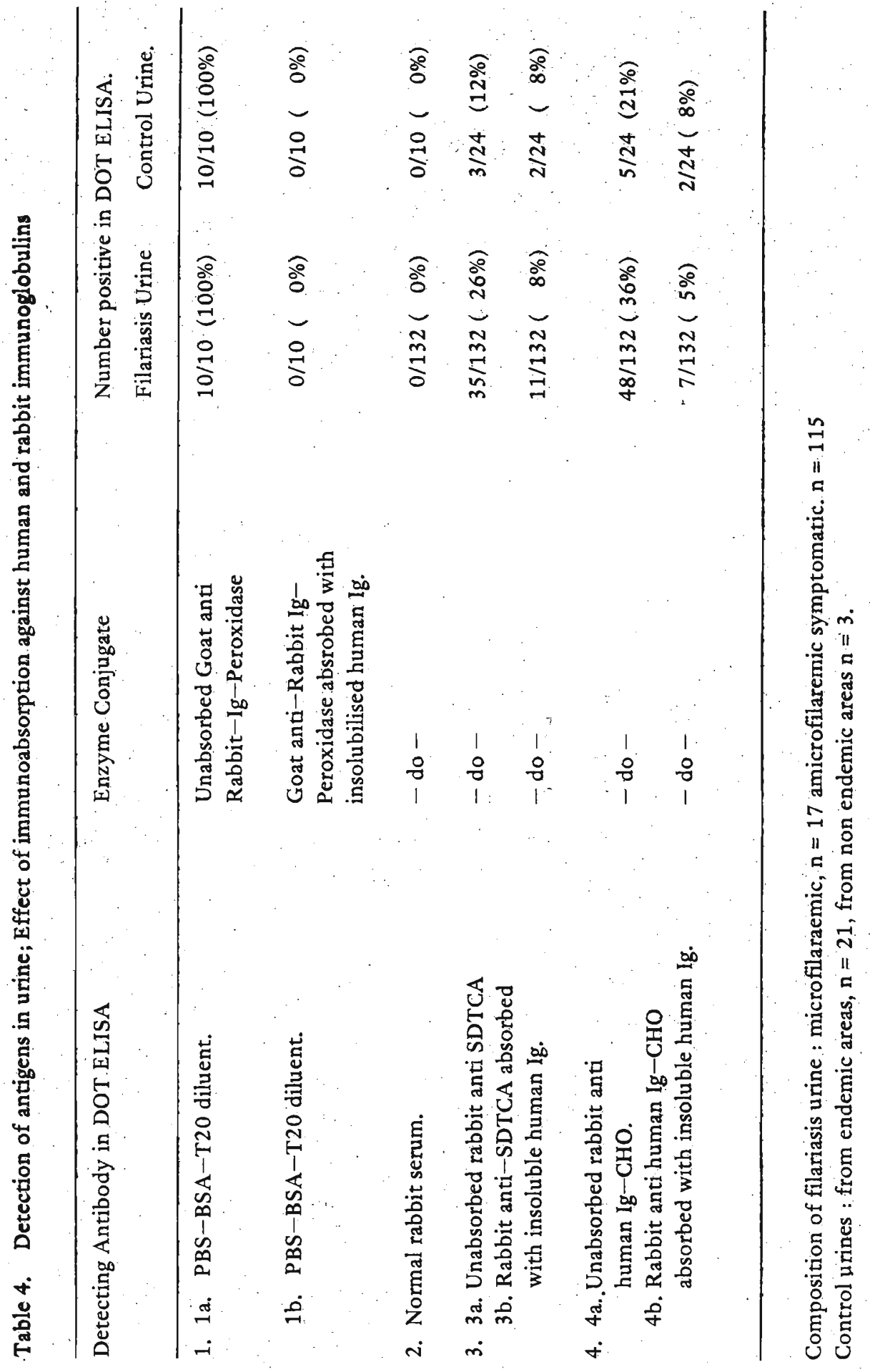


value. However, as observed in Western blot analysis, certain filarial specific epitopes are likely to be present in this complex mixture. Attempts to isolate such epitopes have so far been unsuccessful.

The antibodies in $W$. bancrofti infections reacting with determinants in SDTCA as determined by ELISA were predominantly IgM. The levels of total antibody showed a significant correlation with the level of IgM antibodies. Such dominance of IgM antibody responses has been reported in brugian filariasis. ${ }^{17}$

Immunoprecipitation results summarised in Table 3 demonstrate that rabbit antisera to human Ig, human Ig carbohydrates and $10 \%$ TCA extracts of normal human serum and the filarial parasite $S$. digitata show antigenic cross reactivity. Similarly, radiolabelled human Ig and 10\% TCA extract of normal human serum showed comparable reaction with antisera to human Ig and carbohydrates of the filarial parasite $S$. digitata. The comparable reactions observed with the rabbit antiserum to human immunoglobulin carbohydrates show that the cross reacting epitopes were present in the carbohydrate fractions.

The observed cross reactivities between immunoglobulins and parasite derived carbohydrates were not due to contaminating cattle immunoglobulins which could have been present on the parasite surface. Adult $S$. digitata dwells in the peritoneal cavity and as such are not exposed to serum immunoglobulins. We were unable to detect cattle Ig in concentrated washings of the parasites. Also, cryostat sections of the parasite did not show detectable staining of immunoglobulins by immunofluorescence.

Table 4 shows that urines of some filarial patients and non-filarial subjects contained substances that reacted with antisera to immunoglobulins, Ig carbohydrates and parasite carbohydrates. While it is very likely that certain filarial antigens are excreted in urine, ${ }^{6,26}$ we are unable to explain the residual reactivity seen with non-filarial urines. The possibility of subclinical infection is unlikely in these subjects. Although most of these reactivities could be abolished by absorption with insoluble immunoglobulins (evidence of antigen sharing), 5-8\% of the urines remained positive even after several absorptions. We have consistently observed that certain urines contain molecules reacting with anti-immunoglobulin sera (apparently not species specific) which could not be removed by absorption against insoluble Ig. A possible explanation is that these epitopes are hidden in the intact molecule, but are expressed in the catabolic products. It is also possible that these are derived from other tissue components. 9,13

The findings in this report extend the previous studies on host antigen sharing $2,16,19-24,27-30$ to heterologous immunoglobulin carbohydrates. This has not been reported previously. Such cross reacting molecules were 
present in both blood serum and urine. These molecules are likely to affect the specificity and sensitivity of immunodiagnostic tests, particularly when antigen determination is attempted. ${ }^{7,14}$

\section{Acknowledgements}

This study received financial support from the Directorate General for Science, Research and Development Joint Research Centre of the Commission of the European Communities (Grant No. TSD-M-409 to S. Dissanayake). Excellent technical and computer assistance of Miss. S.C. Galahitiyawa is gratefully acknowledged.

\section{References}

1. BATTEIGER, B., NEWHALL, W.J. \& JONES, R.B. (1982) The use of Tween 20 as a blocking agent in the immunological detection of proteins transferred to nitrocellulose membranes. J. Immunol. 55 : 297-307.

2. COURT, J.P. \& STOREY, D.M.' (1981) Shared antigens between Litomosoides carinii and its hosts, Sigmodon bispidus and Mastomys natalensis. Tropenmed. Parasitol. : 32 : :161-164.

3. DISSANAYAKE, S. \& ISMAIL, M.M. (1980) Antigens of Setaria digitata, cross reaction with surface antigens of $W$. bancrofti microfilariae and serum antibodies of W. bancrofti infected subjects. Bull. W.H.O. 58: 649-654.

4. DISSANAYAKE; S., GALAHITIYAWA; S.C. \& ISMAIL, M.M. (1983) Immune complexes in Wucbereria bancrofti infection in man. Bull. W.H.O. 60: 919-927.

5. DiSSANAYAKE, S., GALAhITIYAWA, S.C. \& ISMAIL, M.M. (1983) Further characterization of filarial antigens by SDS polyacrylamide gel electrophoresis. Bull. W.H.O. $61: 725-730$.

6. DISSANAYAKE, S., FORSYTH, K.P., ISMAIL, M.M. \& MITCHELL, G.F. (1984) Circulating antigens in bancroftian filariasis. Amer. J. Trop. Med. Hyg. 33(6) : $1130-1140$.

7. DISSANAYAKE, S. \& ISMAIL, M.M. (1987) Immunodiagnosis of bancroftian filariasis CIBA Foundation Symposium No. 127:203-214.

8. FORSYTH, K.P., KAZURA, S.R., BROWN, G.V., HEYWOOD, P., DISSANAYAKE, S. \& MITCHELL, G.F. (1985) A monoclonal antibody-based immunoradiometric assay for detection of circulating antigen in Bancroftian filariasis. J. Immunol. 134: 1172-1177. 
9. HERD, J.K., FORREST, T. \& TSCHIDA, J. (197.6) Separation of dermatin sulfate from heparin sulfate in mucopolysaccharidosis urine by chromotography on sephadex g-75. Clin. Chim. Acta. $68: 1-9$.

10. HUDSON, L. \& HAY, F.C. (1976) In "Practical Immunology" Chapter 7. Blackwell Scientific Publications.

11. HUNTER, W.M. \& GREENWOOD, F.C. (1962) Preparation of 131 iodine labelled growth hormone of high specific activity. Nature, 194: $495-496$.

12. JAYAWARDENE, L.J. \& WIJAYARATNAM, V. (1968) The fluorescent antibody test in the serological diagnosis of the causative organisms of tropical pulmonary oesinophilia and filariasis. J. Helmintbol. 42: 57-64.

13. KOFOED, J.A., BARCELO, A.C. \& TOCCI, A.A. (1976) Further studies on gel filteration of urinary substances. Experientia. $32: 851-852$.

14. LAWRENCE, T.G. \& SCHANTZ; P.M. (1985) Do Toxocara canis larval antigens used in enzyme linked immunosorbent assay for visceral larva migrans cross react with $\mathrm{AB}$ isohaemagglutinins and give false positive results. Z. Parasitkund. 71 : $395-400$.

15. LOWRY, H.O., ROSEBOROUGH, N.J., LEWIS, F.R. \& RANDALL, R.J. (1951) Protein measurement with the Folin Phenol reagent. J. Biol. Cbem. 193 : 265-268.

16. McGREEVY, P.B., ISMAIL, M.M., PHILLIPPS, T.M. \& DENHAM, D.A. (1975) Studies with Brugia Pabangi 10. An attempt to demonstrate the sharing of antigenic determinants between the worm and its hosts. J. Helminthol. 49: 107-113.

17. McGREEVY, P.B., RATIWAYANTO, S., TUTI, S., McGREAVY, M.M. \& DENNIS, D.T. (1980) Brugia malayi : relationship between anti sheath antibodies and amicrofilaremia in natives living in an endemic area south of Kalimantan Borneo. Amer. J. Trop. Med. Hyg. 29: 553-562.

18. NORRIS, J.R. \& RIBBONS, D.W. (1970) Total carbohydrate measurement. In "Methods in Microbiology" Vol. 5B, Chapter III: Academic Press Inc. (London) Ltd.

19. OLIVER GONSALEZ, G.L. (1946) Functional antigens in helminths. $J$. Infect. Dis. 78 232-237.

20. OLIVER GONSALEZ, G.L. (1946) Immunological relationships among polysaccharides from various infectious organisms. J. Infect. Dis. 79: 221-225.

21. OLIVER GONSALEZ, G.L. (1949) Release of the A2-isohaemagglutininogen like substances of infectious organisms into human blood serum. J. Infect. Dis. 85 : 66-71. 
22. OliVER GONSALEZ, G.L. \& TORREGOSA, M.W. (1944) Substances in animal parasites related to the human isoagglutinins. J. Infect. Dis. 74 : 173-177.

23. PHILIPP, M., WORMS, M.J., McLAREN, D.J., OGILVIE, B.M., PARKHOUSE, R.M. \& TAYLOR, P.M. (1984) Surface proteins of a filarial nemotode: a major soluble antigen and a host component on the cuticle of Litomosoides carinii. Parasite Immunol: 6 : 63-82.

24. RAO, Y.V.B.G., MEHTA, K., SUBRAMANIAM, D. \& RAO, C.K. (1980) Sharing of antigens between $W$. bancrofti and L. carinii. Ind. J. Med. Res. $72: 47-52$.

25. REDDY, M.V.R., MALHOTRA, A. \& HARINATH, B.C. (1984) Detection of circulating antigen in bancroftian filariasis by sandwich ELISA using filarial serum IgG. J. Helmintbol. 58 : 259-262.

26. REDDY, M.V.R., HARRINATH, B.C. \& HAMILTON, R.G. (1984) Detection of filarial antigen in urine of humans with Wucbereria bancrofti infection by Immunoradiometric assay. Ind. J. Exp. Biol. $22: 515-519$.

27. RIDLEY, D.S. \& HEDGE, E.C. (1977) Immunofluorescent reactions with microfilariae 2. Bearing on host parasite relations. Trans. R. Soc. Trop. Med. Hyg. 71 : $522-524$.

28. SMITH, H.V., KUSEL, J.R. \& GIRDWOOD, R.W.A. (1983) The production of human $\mathrm{A}$ and $\mathrm{B}$ blood group like substances by in vitro maintained second stage Toxocara canis larvae : their presence on the outer larval surfaces and in their excretions/secretions. Clin. Exp. Immunol. 54 : 625-633.

29. SOULSBY, E.J.L. \& COOMBS, R.R.A. (1959) Studies on blood gtoup substances associated with Ascaris lumbricoides. Parasitol. 49 : 505-510.

30. STOREY, D.M. \& COURT, J.P. (1977) In search of host or host like antigens in cotton rat filariasis. Parasitol. $75:$ R9-R10.

31. TOWBIN, H., STAEHELIN, T. \& GORDON, J. (1979) Electrophoretic transfer of proteins from polyacrylamide gels to nitrocellulose sheets : Procedure and some applications. Proc. Nat. Acad. Sci. 76 : 4350-4354.

32. WEIL, G.J., MALANEE, M.S., POWERS, K.G. \& BLAIR, L.S. (1985) Monoclonal antibodies to parasite antigens found in the serum of Dirofilaria immitis infected dogs. J. Immunol. 134 : 1185-1191. 